\title{
pH-Dependent Interaction between C-Peptide and Phospholipid Bicelles
}

\author{
Sofia Unnerståle and Lena Mäler \\ Department of Biochemistry and Biophysics, Center for Biomembrane Research, The Arrhenius Laboratories for Natural Sciences, \\ Stockholm University, 10691 Stockholm, Sweden \\ Correspondence should be addressed to Lena Mäler, lena.maler@dbb.su.se
}

Received 19 April 2012; Accepted 22 May 2012

Academic Editor: Andreas Herrmann

Copyright () 2012 S. Unnerståle and L. Mäler. This is an open access article distributed under the Creative Commons Attribution License, which permits unrestricted use, distribution, and reproduction in any medium, provided the original work is properly cited.

C-peptide is the connecting peptide between the A and B chains of insulin in proinsulin. In this paper, we investigate the interaction between C-peptide and phospholipid bicelles, by circular dichroism and nuclear magnetic resonance spectroscopy, and in particular the $\mathrm{pH}$ dependence of this interaction. The results demonstrate that $\mathrm{C}$-peptide is largely unstructured independent of $\mathrm{pH}$, but that a weak structural induction towards a short stretch of $\beta$-sheet is induced at low $\mathrm{pH}$, corresponding to the isoelectric point of the peptide. Furthermore, it is demonstrated that C-peptide associates with neutral phospholipid bicelles as well as acidic phospholipid bicelles at this low $\mathrm{pH}$. C-peptide does not undergo a large structural rearrangement as a consequence of lipid interaction, which indicates that the folding and binding are uncoupled. In vivo, local variations in environment, including $\mathrm{pH}$, may cause C-peptide to associate with lipids, which may affect the aggregation state of the peptide.

\section{Introduction}

50 years ago, it was discovered that insulin is synthesized as proinsulin, which contains not only the two chains of insulin, $\mathrm{A}$ and $\mathrm{B}$, but also a linker peptide, called C-peptide $[1,2]$. Cpeptide connects the two chains of insulin, which facilitates the disulfide bond formation between them and aids the folding process of insulin $[3,4]$. Since the discovery, several biological effects of C-peptide have been demonstrated [57].

The primary structure of C-peptide varies significantly between different species, although certain common structural features can be observed. For example, the highly acidic and somewhat conserved $\mathrm{N}$-terminus has properties that appear to be important for C-peptides chaperon-like effects on insulin disaggregation [8]. Further, the C-terminus is somewhat conserved and is likely to be involved in receptor interactions [9-11]. Human C-peptide, which is studied in this paper, consists of 31 aminoacid residues, EAEDLQVGQVELGGGPGAGSLQPLALEGSLQ. It contains many negatively charged amino acid residues and no basic residues resulting in a very low $\mathrm{pI}$ (3.5).
Human C-peptide has a random coil structure in buffer, while the $\mathrm{N}$-terminal, third of the $\mathrm{C}$-peptide (residues 111), has been demonstrated to be helical in $95 \%$ TFE [12]. In $\mathrm{H}_{2} \mathrm{O} / \mathrm{TFE} 1: 1$, on the other hand, it has been shown that residues A2 through L5 adopt a type I $\beta$-turn, while residues E27 through Q31, the so-called pentapeptide, is the most ordered part of C-peptide adopting a type III' $\beta$-turn [13]. Further, residues Q9-L12, residues G15-A18 and residues Q22-A25 were all shown to have structural preferences in the NMR-derived ensemble average [13]. It has recently been demonstrated that C-peptide also has the ability, under certain conditions, such as low $\mathrm{pH}$, to form $\beta$-sheet structure, resembling amyloid structures $[14,15]$. The peptide forms predominantly low-order oligomers [14], but very low concentrations of amyloid-like structures may also form [15]. The formation of amyloid structure can be enhanced in the presence of subcritical micelle concentration (CMC) amounts of SDS (at low $\mathrm{pH}$ ), while SDS in amounts above the CMC, on the other hand, promote a more $\alpha$-helical structure [15].

Even though C-peptide appears to only be marginally structured in aqueous solution and in solvents such as TFE, 
its ability to transiently adopt a variety of structures appears to be of importance for the peptides aggregation propensities. The ability of peptides and proteins to self-associate has been recognized in several diseases, including Alzheimer's disease, amyotrophic lateral sclerosis, and type II diabetes $[16,17]$. In many cases, it has been demonstrated that the membrane may serve as a means for peptides to undergo structural rearrangements, which may be important for misfolding events. For the APP A $\beta$ peptide, the composition of the membrane has been shown to be crucial for formation of amyloid structure [18-20]. Due to this feature of the peptide, and its previously demonstrated interaction with SDS, we have in this study examined the interaction between C-peptide and membrane mimetic media composed of isotropic phospholipid bicelles [21-26]. To compare, we have also examined the structure of C-peptide in different large unilamellar vesicle solvents. Further, since it has been demonstrated that $\mathrm{pH}$ is an important factor that governs the aggregation state of C-peptide [15], much like for the APP A $\beta$ peptide [27] we have investigated the effect of $\mathrm{pH}$ on its structure and lipid interaction properties. In this way, the basic biophysical properties of C-peptide have been deduced, and this study shows that $\mathrm{pH}$ affects the ensemble average of the structure of C-peptide, which in turn affects the interaction with membrane-mimicking systems.

\section{Materials and Methods}

2.1. Materials and Sample Preparation. C-peptide was purchased from PolyPeptide Laboratories, France and used without further purification. 1-palmitoyl-2-oleoyl-snglycero-3-phosphocholine (POPC) and 1-palmitoyl-2oleoyl-sn-glycero-3-phospho-(1'-rac-glycerol)(POPG) were used to produce large unilamellar vesicles (LUVs). Deuterated lipids, 1,2-dihexanoyl- $\mathrm{d}_{22}$-sn-glycero-3-phospho-cho-line ( $\mathrm{d}_{22}$-DHPC), 1,2-dimyristoyl-d $\mathrm{d}_{54}$-sn-glycero3 -phosphocholine ( $\mathrm{d}_{54}$-DMPC) and 1,2-dimyristoyl- $\mathrm{d}_{54}$-snglycero-3-phospho-( $1^{\prime}$-rac-glycerol) $\left(\mathrm{d}_{54}\right.$-DMPG) were used to produce bicelles. All phospholipids were obtained from Avanti Polar Lipids (Alabaster, AL, USA). Different buffers were used to study how the $\mathrm{pH}$ affects the C-peptide, three sodium phosphate buffers of $\mathrm{pH} 5.8,6.9$, and 7.2 and one citrate buffer of $\mathrm{pH} 3.2$.

Large unilamellar vesicles (LUVs) were produced for studying the interaction between C-peptide and bilayers by circular dichroism (CD). First, $20 \mathrm{mM}$ stock solutions of neutral and $50 \%$ negatively charged vesicles were prepared by dissolving POPC and POPC/POPG $1: 1$, respectively, in chloroform. The samples were then dried under a flow of $\mathrm{N}_{2}$ gas to create lipid films. To ensure that no chloroform remained, the samples were stored under vacuum overnight. The dried lipid films were then soaked in buffer and vortexed for 10 minutes to obtain a more defined size distribution. The solutions were subsequently subjected to five freezethaw cycles to decrease lamellarity. Finally, to obtain uniform samples of LUVs, the samples were extruded around 20 times through a polycarbonate microfilter with $100 \mathrm{~nm}$ pore size. The CD samples were then prepared from these stock solutions and from stock solutions of $100 \mu \mathrm{M}$ C-peptide to a final concentration in the CD samples of $50 \mu \mathrm{M}$ C-peptide and $1 \mathrm{mM}$ POPC or POPC/POPG $1: 1$ in $50 \mathrm{mM}$ buffer (citrate buffer at $\mathrm{pH} 3.2$ and sodium phosphate buffer at $\mathrm{pH}$ 5.8 or $\mathrm{pH} 6.9$ ).

Small isotropic bicelles were used to further investigate membrane interaction of C-peptide by diffusion NMR and 2D total correlation spectroscopy (TOCSY). For samples used in pulse field gradient (PFG) diffusion measurements, the peptide was initially dissolved in buffer solution $\left(\mathrm{D}_{2} \mathrm{O}\right)$, and lipids were added to each solution. Buffer solutions of $\mathrm{pH} 3.2,5.8$, and 7.2, prepared from $50 \mathrm{mM}$ citrate buffer $(\mathrm{pH}$ 3.2) or sodium phosphate buffer $(\mathrm{pH} 5.8$ or $\mathrm{pH} 7.2)$ were dried and subsequently dissolved in $\mathrm{D}_{2} \mathrm{O} .250 \mu \mathrm{M}$ C-peptide was dissolved in each buffer by sonication in a water bath for $1 \mathrm{~min}$. PFG NMR experiments were acquired to measure the self-diffusion of C-peptide, $D_{\text {free }}$. Subsequently $\mathrm{d}_{54}$-DMPC lipids and $\mathrm{d}_{22}$-DHPC dissolved in $\mathrm{D}_{2} \mathrm{O}$ were added in a ratio of $1: 2$ to each of the three different samples. This resulted in a final total lipid concentration of $150 \mathrm{mM}$ and a qratio (long-chain phospholipids/short-chain phospholipids) of 0.5. After spectra were recorded for these samples, DMPG was added to the three samples, corresponding to $10 \%$ of the total long-chain lipids. In this way, bicelles with $10 \%$ negative charge were obtained. For 2D TOCSY NMR measurements, $200 \mu \mathrm{M}$ peptide was dissolved in DMPC/DHPC or in (DMPC/DMPG 9:1)/DHPC, respectively. Here, the total lipid concentration was $300 \mathrm{mM}$, and the q-ratio was 0.25 . All bicelle mixtures were vortexed until a clear low-viscous solution was formed.

2.2. Circular Dichroism. The measurements were acquired on a Chirascan CD spectrometer with a $1 \mathrm{~mm}$ quartz cell for samples with $50 \mu \mathrm{M}$ peptide content and $1 \mathrm{mM}$ POPC or POPC/POPG $1: 1$. The temperature was adjusted to $298 \mathrm{~K}$ with a TC 125 temperature control. Wavelengths ranging from 190 to $250 \mathrm{~nm}$ were measured with a $0.5 \mathrm{~nm}$ step resolution. Spectra were collected and averaged over ten measurements. Background spectra of buffers, POPC and POPC/POPG 1:1 without any peptide, were also recorded and were subtracted from the peptide spectra.

2.3. NMR Spectroscopy. Translational diffusion experiments were performed on a Bruker Avance spectrometer, equipped with a triple resonance probe-head and operating at a ${ }^{1} \mathrm{H}$ frequency of $600 \mathrm{MHz}$. A standard sample of $0.01 \% \mathrm{H}_{2} \mathrm{O}$ in $\mathrm{D}_{2} \mathrm{O}$, with $1 \mathrm{mg} / \mathrm{mL} \mathrm{GdCl}_{3}$ to avoid radiation damping, was used for calibration of the gradient strength. The temperature was adjusted to $298 \mathrm{~K}$ using $\mathrm{d}_{4}$-methanol. Diffusion constants were measured using a modified StejskalTanner spin-echo experiment [28-30] using a fixed diffusion time $(300 \mathrm{~ms})$ to minimize the influence of relaxation contributions, and a fixed gradient length $(2.4 \mathrm{~ms}$ in buffer, $3 \mathrm{~ms}$ in bicelle solution, and $3.4 \mathrm{~ms}$ in acidic bicelle solution) and with a gradient strength varying linearly over 32 steps. The linearity of the gradient was calibrated as described previously [31]. The diffusion coefficient for HDO was measured and compared to the standard diffusion of HDO 
in $\mathrm{D}_{2} \mathrm{O}\left(1.910^{-9}\right)$ [32]. This ratio was then multiplied to all measured diffusion constants to correct for viscosity differences induced by the sample.

2D TOCSY experiments [33] were recorded on Bruker Avance spectrometers operating at ${ }^{1} \mathrm{H}$ frequencies of $500 \mathrm{MHz}$ or $600 \mathrm{MHz}$ at $298 \mathrm{~K}$. TOCSY spectra were recorded with mixing times of $30 \mathrm{~ms}$. Typically, 24-48 transients were recorded, and the number of increments in the indirect dimension was 256-512. The assignment of the spectra was achieved by the aid of the assignment by Munte et al. with the BMRB accession code 6623 [13], which was made at $\mathrm{pH} 7.0$ and at $283 \mathrm{~K}$. No chemical shift differences larger than $\pm 0.03 \mathrm{ppm}$ were seen between this assignment and our spectra obtained at $\mathrm{pH} 5.8$ and at $298 \mathrm{~K}$.

\section{Results}

3.1. C-Peptide Shows Overall Random Coil Features. Other studies have shown that C-peptide is predominately unstructured in aqueous solution and in the presence of lipid vesicles at $\mathrm{pH} 5$ and 7 [12]. This is also seen in our CD spectra (Figures 1(b) and 1(c)), which show random coil features in buffered solutions, POPC and POPC/POPG $1: 1$, respectively. It has previously been shown that SDS induces oligomerization of C-peptide at a $\mathrm{pH}$ close to the $\mathrm{pI}$ of $\mathrm{C}$ peptide (around 3.5) [15]. Thus, we wanted to study the structure of C-peptide at lower pH. Also at pH 3.2, C-peptide is predominantly in a random coil conformation and our results indicate that no major structural rearrangements are induced as a consequence of adding POPC or POPC/POPG $1: 1$, respectively (Figure $1(\mathrm{a})$ ). The lack of structural induction indicates that there are no tight C-peptide-vesicle complexes formed, or that the peptide does not undergo large structural rearrangements in the presence of bilayers. However, local structural rearrangements or weak ensemble average preferences for the overall structure too small to be detected by far-UV CD may be significant for lipid interactions [34]. Such rearrangements may be detected in the $\mathrm{H}^{N}-\mathrm{H}^{\alpha}$ region in TOCSY spectra, since the $\mathrm{H}^{\alpha}$ chemical shifts are especially sensitive to local environment [35].

\subsection{Chemical Shift Changes Reveal That Structural Rearrange-} ments Are Induced by Lowering the $\mathrm{pH}$. Even though the Cpeptide is predominately unstructured at all $\mathrm{pH}$ studied in this paper as seen in CD spectra (Figures $1(\mathrm{a})-1(\mathrm{c})$ ), lowering the $\mathrm{pH}$ was observed to induce a slightly different population average of structures as evidenced by small shift changes in 2D TOCSY spectra (Figure 2(a)). The peaks were generally observed to become less dispersed at $\mathrm{pH} 3.2$ as compared to at $\mathrm{pH}$ 5.8. By comparing the chemical shifts under these two conditions, more detailed information can be gained (Figure 2(b)). The amino acid residues that show the greatest chemical shift differences between $\mathrm{pH} 3.2$ and pH 5.8 are the terminal glutamine Q31, probably due to its greater solvent accessibility, and the negatively charged residues E3, D4, E11, and E27 (the N-terminal E1 is not visible in the spectra). These negatively charged amino acid residues are less likely to be charged at pH 3.2 (close to the $\mathrm{pI}$ of the C-peptide) due to protonation, which most likely is the main reason for the differences in chemical shifts. Other amino acid residues that are significantly affected by the change in $\mathrm{pH}$ are $\mathrm{A} 2$ and Q6. The $\mathrm{H}^{\alpha}$ chemical shifts for both these residues are likely to be influenced by the change in environment of E1 and E3; nevertheless, significant chemical shift changes are observed for a large part of the $\mathrm{N}$-terminus of C-peptide.

To investigate if these chemical shift differences are of importance for local structure induction, secondary chemical shifts were calculated for the $\mathrm{H}^{\alpha}$ protons (Figure 3 ) [35]. When comparing the secondary chemical shifts at $\mathrm{pH}$ 3.2, 5.8, and 7, two stretches of amino acid residues are seen to move towards higher secondary chemical shift values with decreasing $\mathrm{pH}$, residues $\mathrm{A} 2$ through $\mathrm{Q} 6$, and residues Q9 through L12, although the secondary chemical shift values are not consistently positive or negative in the first stretch of residues. These regions correspond well with two out of the five local structured regions previously found by Munte et al. in the C-peptide solution structure in $\mathrm{H}_{2} \mathrm{O} /$ TFE $1: 1$ [13]. Three amino acid residues not located in this region also have the same pattern, G17, Q22 and E27. Since most of these amino acid residues are located close to acidic residues, these shift changes can be induced by protonating the charged residues and are not necessarily due to a $\mathrm{pH}$-induced structural rearrangement. In Figure 3, three residues in a row with a secondary chemical shift above 0.1 indicates $\beta$-sheet structure. Such a stretch is found at the lower $\mathrm{pH}$ (3.2), that is, V10-L12, indicating a tendency for $\beta$-sheet structure for this small part of the sequence. This corresponds well with previous studies, which identified residues Q9-L12 as being capable of forming $\beta$-turns in $\mathrm{H}_{2} \mathrm{O} / \mathrm{TFE} 1: 1[13]$ and showed that lower $\mathrm{pH}$ is needed to induce $\beta$-structure, but then in the presence of SDS [15]. Here, we show that this small structural arrangement can be induced without any strong structural inducers like TFE or $\mathrm{SDS}$, just by changing the $\mathrm{pH}$. When correcting for nearestneighbor effects according to Wishart et al. [36] (data not shown) G15, Q22, and L24 were the residues that were most affected, all moving to negative secondary chemical shifts with values larger than -0.1 .

In summary, lowering the $\mathrm{pH}$ induces small but significant chemical shift changes due to changed preferences in the population average. Some of these changes are most likely due to changes in the protonation state of the acidic residues, while a short N-terminal sequence as well as residues V10L12 is seen to undergo small conformational changes towards more $\beta$-like structures.

3.3. Bicelles Induce Chemical Shift Changes at Low $p H$. To investigate if the shift changes seen between $\mathrm{pH} 5.8$ and $\mathrm{pH}$ 3.2 affect the membrane interaction, we examined changes in the TOCSY spectra when adding DMPC/DHPC bicelles $[37,38]$ with a $q$-ratio of 0.25 to $200 \mu \mathrm{M}$ peptide (giving a total lipid/peptide ratio of $1500: 1$ ) at $\mathrm{pH} 5.8$ (Figure 4) and at $\mathrm{pH} 3.2$ (Figure 5). No shift changes were seen upon adding bicelles at $\mathrm{pH} 5.8$ (Figure 4(a)), and furthermore, no changes were seen when adding $q=0.25$ (DMPC/DMPG 9:1)/DHPC bicelles either (Figure 4(b)). At this pH, Cpeptide has a negative net charge; hence, the association with 


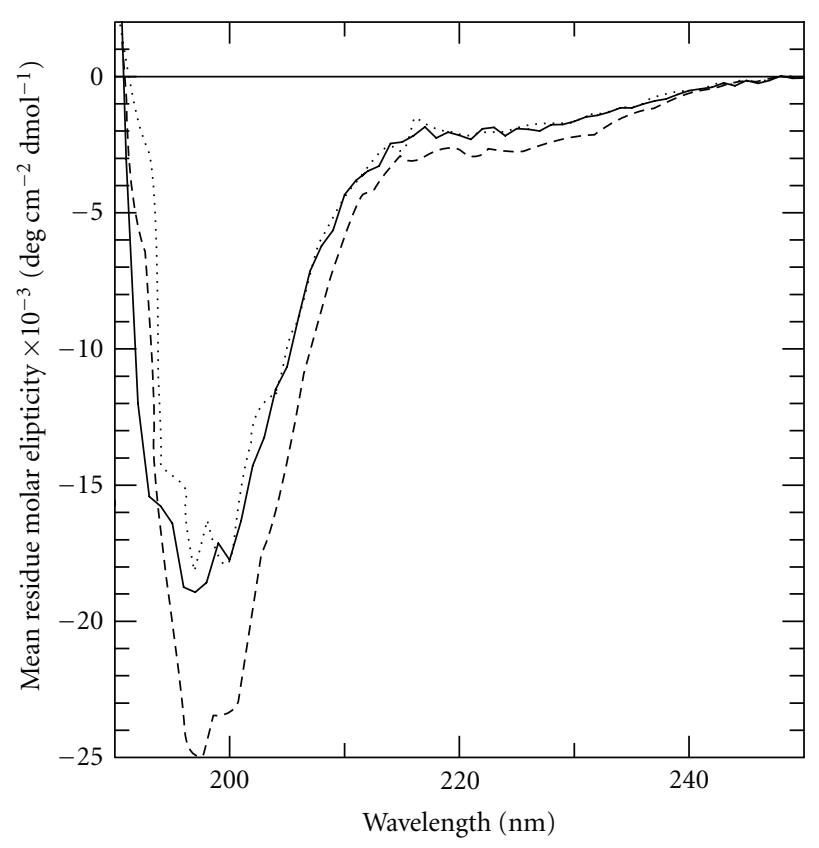

(a)

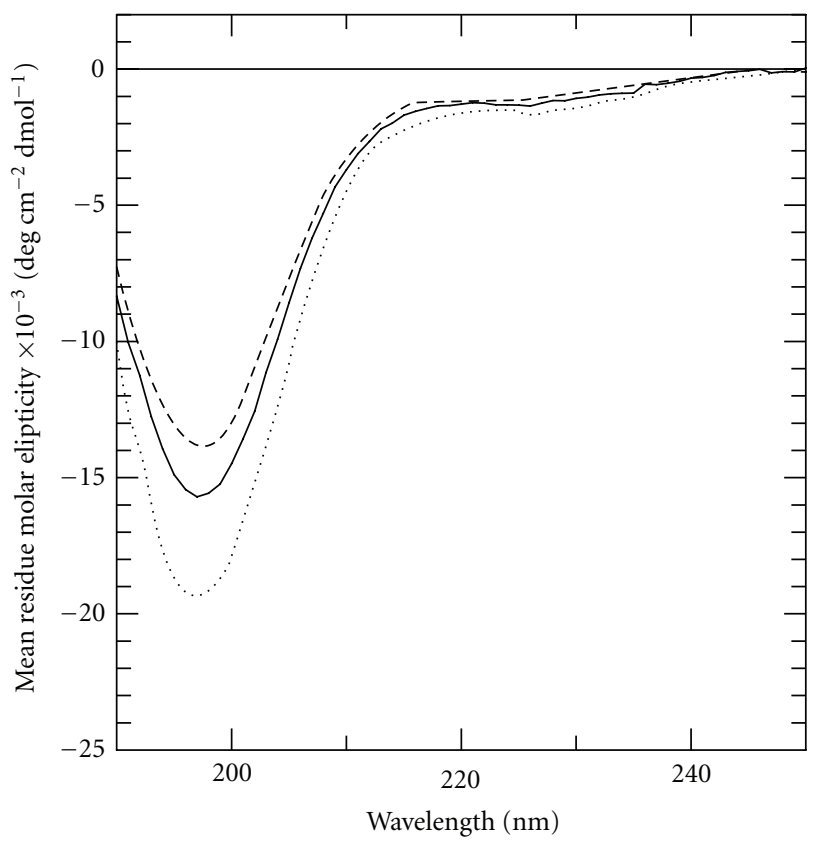

(b)

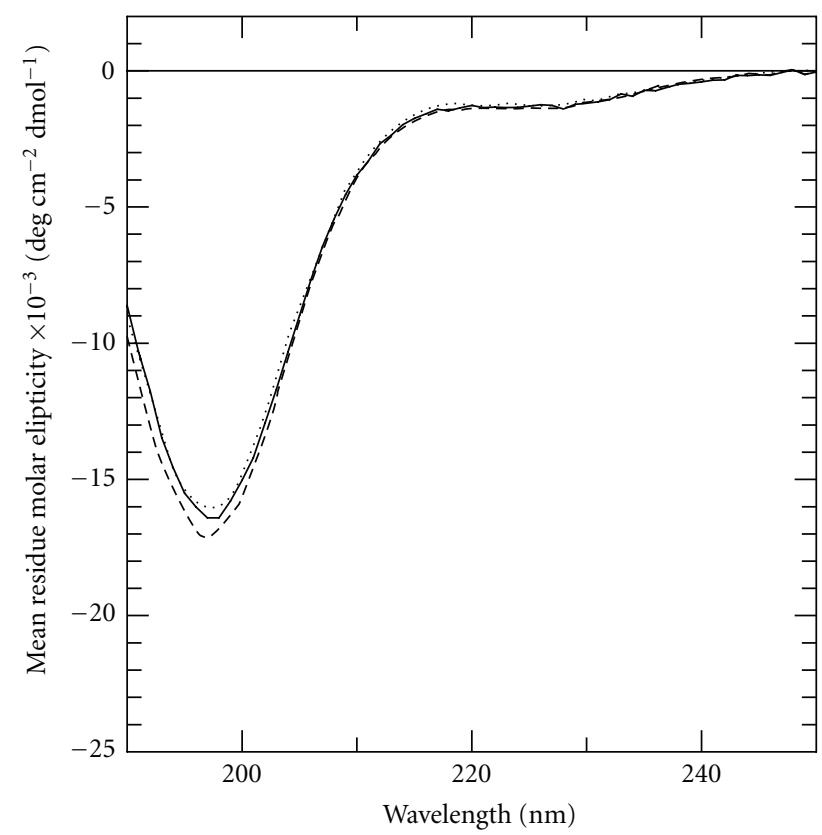

(c)

FIGURE 1: Secondary structure of C-peptide in LUVs at different $\mathrm{pH}$ as determined by CD. The figures depict CD spectra of $50 \mu \mathrm{M}$ C-peptide in buffer (dotted line), in $1 \mathrm{mM}$ POPC (continuous line), and in 1 mM POPC/POPG 1:1 (dashed line). (a) Shows spectra for C-peptide in $50 \mathrm{mM}$ citrate buffer, $\mathrm{pH}$ 3.2, (b) for C-peptide in $50 \mathrm{mM}$ sodium phosphate buffer, $\mathrm{pH}$ 5.8, and (c) for C-peptide in $50 \mathrm{mM}$ sodium phosphate buffer, pH 6.9.

bicelles is not expected to increase by adding negative charges to the membrane. At $\mathrm{pH} 3.2$, on the other hand, chemical shift changes are observed (Figure 5(a)). These chemical shift changes are not for the same residues that were identified as $\mathrm{pH}$-sensitive. Rather, the shifts of A2, D4, L5, V7, Q9, E11, G17, G19, and L26 were affected by adding the bicelles (Figure 5(b)). Out of these residues A2, D4, V7, and E11 move to more $\beta$-sheet like shifts, while L5, Q9, G17, and L26 move to more $\alpha$-helical shifts. The small stretch which was observed to adopt $\beta$-sheet-like shifts in buffer at $\mathrm{pH}$ 3.2 (V10-L12) became even more pronounced when adding bicelles. Hence, the interaction with bicelles stabilizes or favors this structure. Further, this shows that the previously reported structural preferences in C-peptide in TFE are 

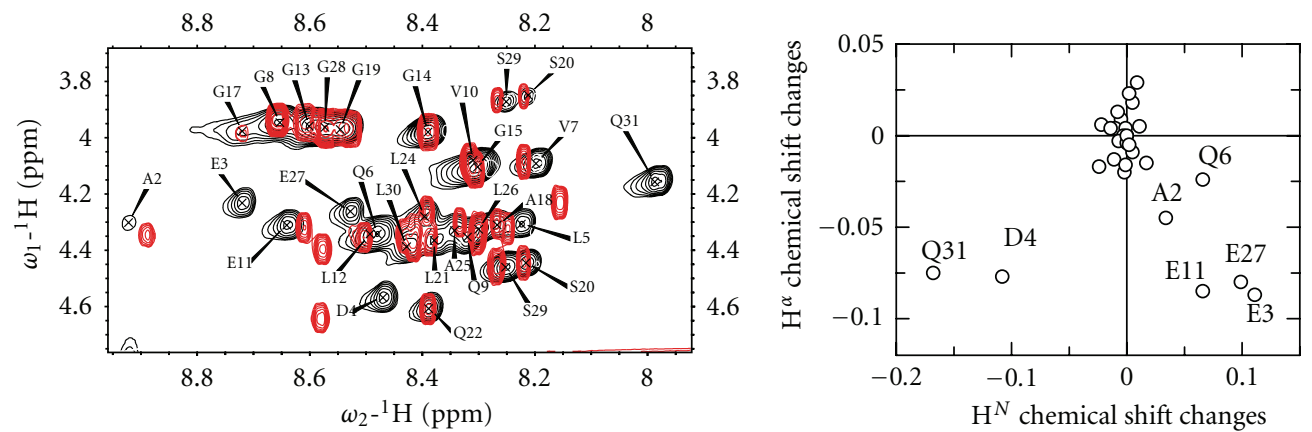

Figure 2: (a) 2D TOCSY spectra recorded at $600 \mathrm{MHz}$ for $200 \mu \mathrm{M}$ C-peptide in $50 \mathrm{mM}$ citrate buffer pH 3.2 (red) and in $50 \mathrm{mM}$ sodium phosphate buffer pH 5.8 (black). (b) Differences in amide proton chemical shifts between pH 3.2 and pH 5.8 (i.e., amide proton shift pH 5.8 and amide proton shift $\mathrm{pH} 3.2$ ) are plotted against differences in $\alpha$ proton chemical shifts (i.e., $\alpha$ proton shift $\mathrm{pH} 5.8$ and $\alpha$ proton shift $\mathrm{pH}$ 3.2).

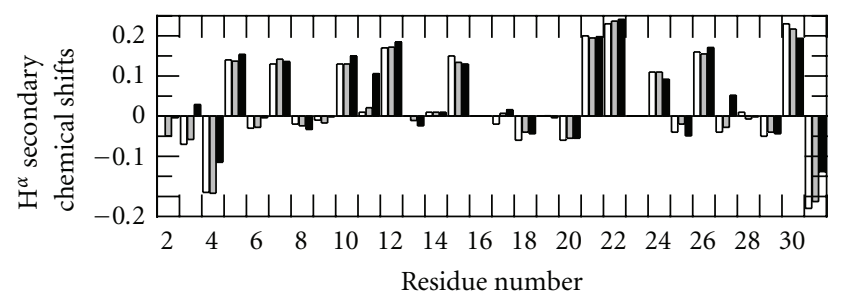

FIGURE 3: (a) $\mathrm{H} \alpha$ secondary chemical shifts for each amino acid residue in C-peptide in pH 7.0 (white), 5.8 (grey), and 3.2 (black).

seen also when using membrane mimetics, suggesting that this stretch may be of relevance in vivo, and may at least transiently interact with lipids.

In summary, we observed small but significant bicelleinduced chemical shift changes at $\mathrm{pH} 3.2$ but not at $\mathrm{pH}$ 5.8, that stabilize the $\beta$-sheet structure of V10-L12.

\subsection{PFG Diffusion Data Show That the Bicelle Association} Is Greater at Lower $\mathrm{pH}$. To investigate the extent of the Cpeptide-lipid interactions, diffusion coefficients were measured in buffer and in the presence of different lipid bicelles. First, the self-diffusion coefficients were measured for Cpeptide $(250 \mu \mathrm{M})$ in $50 \mathrm{mM}$ phosphate buffer of $\mathrm{pH} 5.8$ and 7.2 and in $50 \mathrm{mM}$ citrate buffer of $\mathrm{pH}$ 3.2. These values are shown in Table 1. By using the relationship between the hydrodynamic radius $\left(\mathrm{r}_{\mathrm{H}}\right)$ and the molecular weight $\left(\mathrm{M}_{\mathrm{r}}\right)$ for nonstructured peptides $\left(r_{\mathrm{H}}=0.27 \mathrm{M}_{\mathrm{r}}{ }^{0.50}\right)$ [39] and by using the theoretical molecular weight of the monomer $(3020.3 \mathrm{Da})$, it became evident that the major population of C-peptide under all these conditions is that of a monomeric peptide $\left(D=1.66 \cdot 10^{-10} \mathrm{~m} / \mathrm{s}^{2}\right)$. We, therefore, conclude that only changing the $\mathrm{pH}$ does not induce a detectable amount of oligomerization of C-peptide monomers. Second, the diffusion coefficients for C-peptide in phospholipid bicelles $(150 \mathrm{mM}$ total lipid, $q=0.5)$ with the bilayer part made of DMPC or DMPC/DMPG 9:1 were acquired. Measurements were carried out at similar $\mathrm{pH}$ values as used in the $\mathrm{CD}$ measurements. The diffusion coefficients for C-peptide decreased significantly when adding the phospholipid bicelles at all $\mathrm{pH}$ as seen in Table 1. The populations of free and bicelle-bound molecules can be estimated using a two-state model:

$$
x D_{\text {DMPC }}+(1-x) D_{\text {free }}=D_{\text {mixture }},
$$

where $D_{\text {free }}$ represents the diffusion of free peptide in solution (obtained from measurements in buffer), and $D_{\text {DMPC }}$ is the diffusion coefficient for DMPC, that is, the diffusion rate of the bicelles. It has previously been demonstrated that all DMPC molecules are bicelle-bound, and hence it can be safely assumed that the diffusion coefficient for DMPC represents the diffusion of the bicelle [23-26]. Finally, $D_{\text {mixture }}$ is the measured diffusion coefficient for Cpeptide in the bicelle solution. This calculation suggests that around $65 \%$ of the peptide is bound to both DMPC and DMPC/DMPG bicelles at $\mathrm{pH} 3.2$, when the C-peptide is neutral, while at $\mathrm{pH} 5.8$ and 7.2 only $8-34 \%$ is bound, depending on the type of bicelle and $\mathrm{pH}$. Hence, $\mathrm{pH}$ is important for the degree of association with the bicelles, and negatively charged C-peptide does not associate with the lipids to the same degree as C-peptide at low pH. As seen previously in the chemical shift analyses, charged lipids (DMPG in this case) do not appear to change the interaction.

\section{Discussion}

In this study, we wished to elucidate the effect of $\mathrm{pH}$ on C-peptide structure and lipid interactions. Previous studies have examined the effects of lipids on C-peptide structure at $\mathrm{pH} 5$ or higher, and neither $\mathrm{CD}$ spectroscopy or size exclusion chromatography has revealed any lipid interaction [12]. Hence, it was then concluded that stable conformationdependent interactions of $\mathrm{C}$-peptide with lipid membranes are unlikely to occur. Biological effects of C-peptide, protecting against diabetic complications, are mediated by interaction with insulin or interaction with membrane via specific and/or nonspecific membrane interaction. Most studies support specific interactions with a, yet to be found, GPCR $[40,41]$. However, the D-enantiomer of C-peptide has the same biological activity as the L-enantiomer [42], which suggests that other receptor-independent interactions 

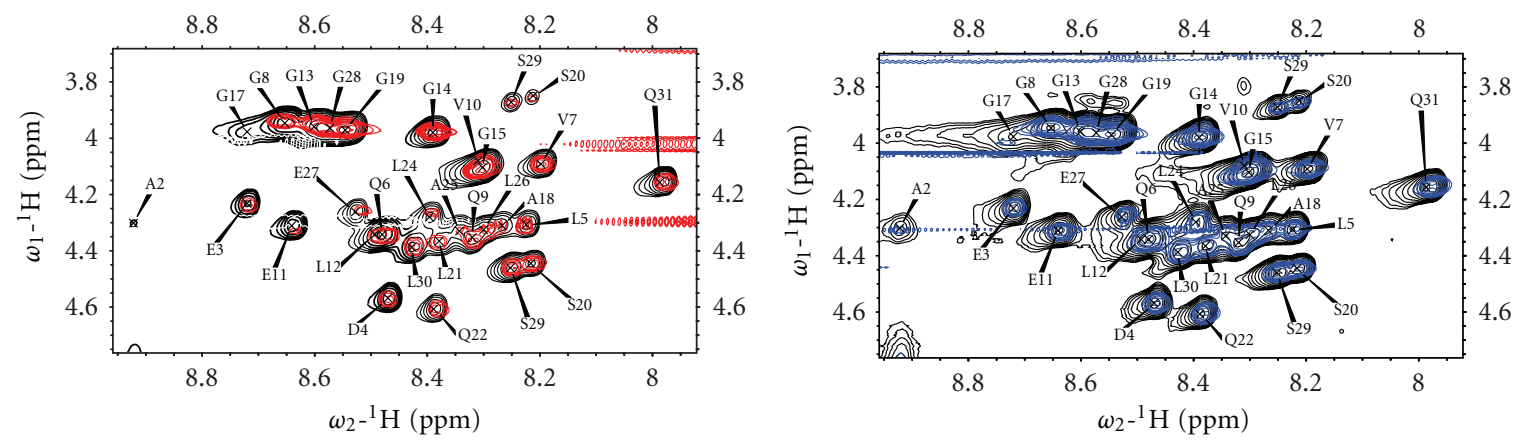

FIGURE 4: (a) 2D TOCSY spectra recorded at $600 \mathrm{MHz}$ for $200 \mu \mathrm{M}$ C-peptide in bicelles (300 mM total lipid, $q=0.25)$ at pH 5.8. The spectra acquired in buffer are shown in black, while the spectra in bicelle solution are shown in (a) red for DMPC/DHPC bicelles and (b) blue for (DMPC/DMPG 9:1)/DHPC bicelles.
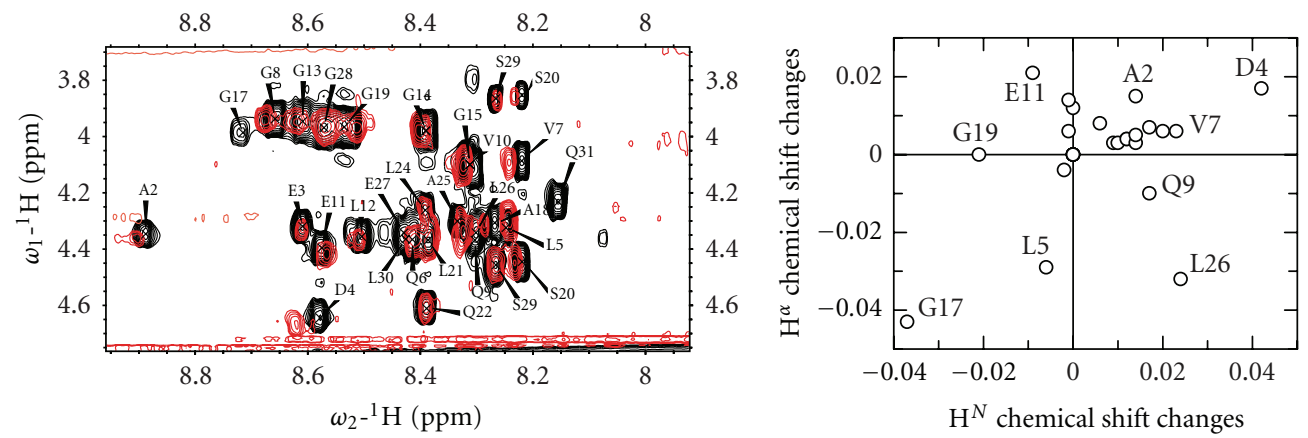

FIGURE 5: (a) 2D TOCSY spectra of $200 \mu \mathrm{M}$ C-peptide in buffer (black) and in DMPC/DHPC bicelles (300 mM total lipid, $q=0.25)$ (red) at $\mathrm{pH}$ 3.2. (b) Differences in amide proton chemical shifts between C-peptide in citrate buffer and C-peptide in DMPC/DHPC bicelles at pH 3.2 are plotted against differences in $\alpha$ proton chemical shifts (i.e., chemical shift in bicelles and chemical shift in buffer).

are important for function. Formation of cation-selective channels in lipid bilayers [43] also suggests a more nonspecific interaction. Hence, we find it valuable to investigate nonspecific interactions between $\mathrm{C}$-peptide and the membrane as a part of $\mathrm{C}$-peptides protective function. We have previously demonstrated that, at low $\mathrm{pH}, \mathrm{C}$-peptide has the ability to form $\beta$-sheet-like aggregates at low detergent concentrations and $\alpha$-helical structure in SDS micelles [15], indicating that $\mathrm{pH}$ is important for structural induction. Thus, the structure and lipid interaction of C-peptide was in the present study also examined at a lower $\mathrm{pH}$ close to the pI of the C-peptide. From the results, we see that Cpeptide favors a lipid interaction at low $\mathrm{pH}$, when the peptide is neutral, (around $65 \%$ of the peptide is associated with bicelles at $\mathrm{pH} 3.2$ ), suggesting that the relationship between electrostatic and hydrophobic interactions is important for this process (Figure 6). By decreasing the $\mathrm{pH}$, small structural rearrangements in predominately the $\mathrm{N}$-terminal and in the amino acid stretch between V10 and L12 are induced, that facilitate lipid interaction. Upon addition of bicelles, these structural preferences are stabilized. The structural rearrangements of C-peptide, as judged from both $\mathrm{CD}$ and NMR spectroscopy are not large, and thus, C-peptide represents a group of membrane interacting peptides that do not appear to undergo large structural changes upon membrane binding. This behavior has previously been observed for, for example, the interaction between the opioid receptor peptide ligands (dynorphins) and bicelles, which did not cause any structural induction in the peptide ligands [34]. It appears that lack of structure induction is not a conclusive way of demonstrating lack of peptide-membrane interaction. Sometimes local and transient structural preferences in an ensemble of peptides dictate function [44]. This is similar to the recent findings that even protein-protein interactions may not always lead to well-formed secondary or tertiary structures, but indicates a novel mode of action of these intrinsically disordered proteins $[45,46]$.

Lipid-peptide interaction can further promote aggregation. It is well known that insulin forms oligomeric states and amyloid fibrils as a function of $\mathrm{pH}$ and ionic strength [19, 3437]. However, C-peptide has also been demonstrated to form oligomers under conditions similar to in vivo situations, including sub- $\mu \mathrm{M}$ concentrations $[12,13]$. Although the interaction between C-peptide and lipids appears to be weak in the present study, the membrane can affect local concentrations of $\mathrm{C}$-peptide and change the local $\mathrm{pH}$, which can shift the equilibrium between C-peptide monomer and membrane bound species. For instance, the interfacial $\mathrm{pH}$ of anionic membranes can be much lower than the bulk $\mathrm{pH}$. This may in turn have an effect on the aggregation of Cpeptide. Local $\mathrm{pH}$ effect has previously been demonstrated to be of importance for, for example, membrane insertion of the $\mathrm{pH}$ (low) insertion peptide (pHLIP), where low $\mathrm{pH}$ promotes interaction with the membrane[47, 48]. 
TABLe 1: Diffusion coefficients for the C-peptide.

\begin{tabular}{ccccccc}
\hline & & \multicolumn{2}{c}{ Diffusion coefficient $\left(10^{-10} \mathrm{~m}^{2} / \mathrm{s}\right)^{\mathrm{a}}$} & \multicolumn{2}{c}{$(\mathrm{DMPC} / \mathrm{DMPG} 4: 1) / \mathrm{DHPC}$} \\
$\mathrm{pH}$ & Buffer & $D_{\text {mixture }}$ & $D_{\text {DMPC }}$ & $x(\%)^{\mathrm{b}}$ & $D_{\text {mixture }}$ & $D_{\text {DMPC }}$ \\
& $D_{\text {free }}$ & $0.8 \pm 0.1$ & $0.48 \pm 0.05$ & 69 & $0.77 \pm 0.1$ & $0.36 \pm 0.05$ \\
\hline 3.2 & $1.5 \pm 0.1$ & $1.4 \pm 0.1$ & $0.43 \pm 0.05$ & 17 & $1.1 \pm 0.1$ & $0.42 \pm 0.05$ \\
7.8 & $1.6 \pm 0.1$ & $1.1 \pm 0.1$ & $0.34 \pm 0.05$ & 34 & $1.4 \pm 0.1$ & $0.25 \pm 0.05$ \\
\hline
\end{tabular}

${ }^{a}$ The diffusion coefficients are normalized according to the diffusion of HDO to account for viscosity differences. ${ }^{b}$ Estimation of the percentage of peptide bound to the phospholipid bicelle as calculated by (1).

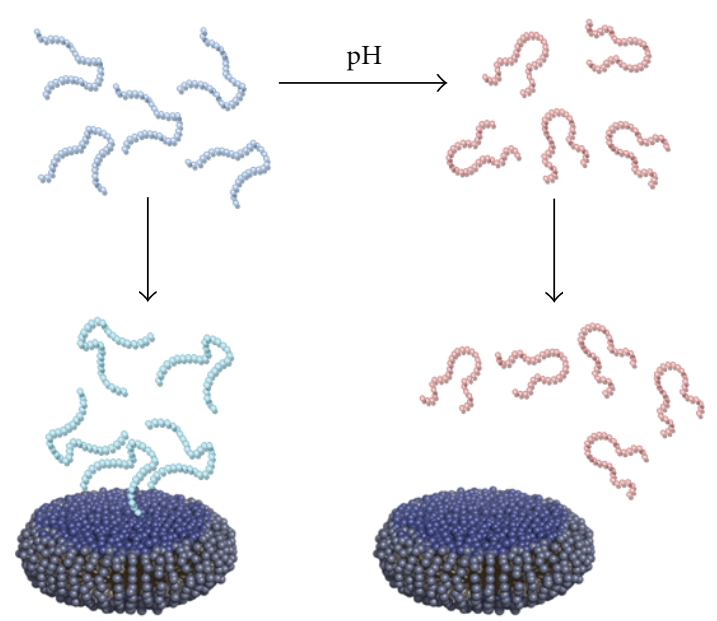

Figure 6: When lowering the $\mathrm{pH}$ to 3.2 (left panel), small structural rearrangements are induced that facilitate interaction with phospholipid bicelles. The interaction with bicelles further influences the structure. At pH 5.8, on the other hand, (right panel), no structural arrangements are seen upon addition of bicelles and the interaction is much weaker.

Although earlier studies have demonstrated that interactions with lipid vesicle bilayers do not result in any membrane-induced structure conversion in C-peptide [12], local variations in environment, including $\mathrm{pH}$, may cause Cpeptide to associate with lipids, as demonstrated here, which may affect the aggregation state of the peptide, and the equilibrium between a dominating population of monomeric peptides and a very small population of oligomers may be shifted [14]. Hence, transient membrane interactions may be of importance in vivo for inducing aggregation without any apparent structure intermediate.

\section{Abbreviations}

TFE: 2,2,2-Trifluoroethanol

SDS: Sodium dodecyl sulfate

CMC: Critical micelle concentration

APP: Amyloid precursor protein

POPC: 1-palmitoyl-2-oleoyl-snglycero-3-phospho-choline

POPG: 1-palmitoyl-2-oleoyl-snglycero-3-phospho-(1-racglycerol)
LUVs: Large unilamellar vesicles

DHPC: 1,2-dihexanoyl-d22-sn-glycero-3phosphocholine

DMPC: 1,2-dimyristoyl-d54-sn-glycero-3phosphocholine

DMPG: 1,2-dimyristoyl-d54-sn-glycero-3phospho-(1-rac-glycerol)

CD: $\quad$ Circular dichroism

NMR: Nuclear magnetic resonance

TOCSY: Total correlation spectroscopy

PFG: Pulse field gradient

D: $\quad$ Diffusion coefficient

GdCl: Gadolinium(III) chloride

BMRB: Biological Magnetic Resonance Bank

$\mathrm{M}_{\mathrm{r}}$ : $\quad$ Molecular weight

$\mathrm{r}_{\mathrm{H}}$ : Hydrodynamic radii

GPCR: G protein-coupled receptor.

\section{Funding}

This work was supported by the Swedish Research Council.

\section{References}

[1] D. F. Steiner, D. Cunningham, L. Spigelman, and B. Aten, "Insulin biosynthesis: evidence for a precursor," Science, vol. 157, no. 3789, pp. 697-700, 1967.

[2] D. F. Steiner and P. E. Oyer, "The biosynthesis of insulin and a probable precursor of insulin by a human islet cell adenoma," Proceedings of the National Academy of Sciences of the United States of America, vol. 57, no. 2, pp. 473-480, 1967.

[3] R. E. Chance, R. M. Ellis, and W. W. Bromer, "Porcine proinsulin: characterization and amino acid sequence," Science, vol. 161, no. 3837, pp. 165-167, 1968.

[4] D. F. Steiner, "Proinsulin and the biosynthesis of insulin," The New England Journal of Medicine, vol. 280, no. 20, pp. 11061113, 1969.

[5] J. Wahren, B. L. Johansson, and H. Wallberg-Henriksson, "Does C-peptide have a physiological role?" Diabetologia, vol. 37, no. 2, pp. S99-S107, 1994.

[6] J. Wahren, K. Ekberg, J. Johansson et al., "Role of C-peptide in human physiology," American Journal of Physiology, vol. 278, no. 5, pp. E759-E768, 2000.

[7] J. Wahren, K. Ekberg, and H. Jörnvall, "C-peptide is a bioactive peptide," Diabetologia, vol. 50, no. 3, pp. 503-509, 2007.

[8] L. M. Chen, X. W. Yang, and J. G. Tang, "Acidic residues on the N-terminus of proinsulin C-peptide are important for the folding of insulin precursor," Journal of Biochemistry, vol. 131, no. 6, pp. 855-859, 2002. 
[9] Y. Ohtomo, T. Bergman, B. L. Johansson, H. Jörnvall, and J. Wahren, "Differential effects of proinsulin C-peptide fragments on $\mathrm{Na}^{+}, \mathrm{K}^{+}$- ATPase activity of renal tubule segments," Diabetologia, vol. 41, no. 3, pp. 287-291, 1998.

[10] R. Rigler, A. Pramanik, P. Jonasson et al., "Specific binding of proinsulin C-peptide to human cell membranes," Proceedings of the National Academy of Sciences of the United States of America, vol. 96, no. 23, pp. 13318-13323, 1999.

[11] A. Pramanik, K. Ekberg, Z. Zhong et al., "C-peptide binding to human cell membranes: importance of Glu27," Biochemical and Biophysical Research Communications, vol. 284, no. 1, pp. 94-98, 2001.

[12] M. Henriksson, J. Shafqat, E. Liepinsh et al., "Unordered structure of proinsulin C-peptide in aqueous solution and in the presence of lipid vesicles," Cellular and Molecular Life Sciences, vol. 57, no. 2, pp. 337-342, 2000.

[13] C. E. Munte, L. Vilela, H. R. Kalbitzer, and R. C. Garratt, "Solution structure of human proinsulin C-peptide," FEBS Journal, vol. 272, no. 16, pp. 4284-4293, 2005.

[14] H. Jörnvall, E. Lindahl, J. Astorga-Wells et al., "Oligomerization and insulin interactions of proinsulin C-peptide: threefold relationships to properties of insulin," Biochemical and Biophysical Research Communications, vol. 391, no. 3, pp. 1561-1566, 2010.

[15] J. Lind, E. Lindahl, A. Perálvarez-Marín, A. Holmlund, H. Jörnvall, and L. Mäler, "Structural features of proinsulin Cpeptide oligomeric and amyloid states," FEBS Journal, vol. 277, no. 18 , pp. 3759-3768, 2010.

[16] C. M. Dobson, "Protein misfolding, evolution and disease," Trends in Biochemical Sciences, vol. 24, no. 9, pp. 329-332, 1999.

[17] C. M. Dobson, "Protein folding and misfolding," Nature, vol. 426, no. 6968, pp. 884-890, 2003.

[18] S. A. Waschuk, E. A. Elton, A. A. Darabie, P. E. Fraser, and J. McLaurin, "Cellular membrane composition defines A $\beta$-lipid interactions," Journal of Biological Chemistry, vol. 276, no. 36, pp. 33561-33568, 2001.

[19] M. Bokvist, F. Lindström, A. Watts, and G. Gröbner, "Two types of Alzheimer's $\beta$-amyloid (1-40) peptide membrane interactions: aggregation preventing transmembrane anchoring versus accelerated surface fibril formation," Journal of Molecular Biology, vol. 335, no. 4, pp. 1039-1049, 2004.

[20] A. Wahlström, L. Hugonin, A. Perálvarez-Marín, J. Jarvet, and A. Gräslund, "Secondary structure conversions of Alzheimer's $\mathrm{A} \beta(1-40)$ peptide induced by membrane-mimicking detergents," FEBS Journal, vol. 275, no. 20, pp. 5117-5128, 2008.

[21] C. R. Sanders and R. S. Prosser, "Bicelles: a model membrane system for all seasons?” Structure, vol. 6, no. 10, pp. 12271234, 1998.

[22] R. R. Vold, R. S. Prosser, and A. J. Deese, "Isotropic solutions of phospholipid bicelles: a new membrane mimetic for high-resolution NMR studies of polypeptides," Journal of Biomolecular NMR, vol. 9, no. 3, pp. 329-335, 1997.

[23] K. J. Glover, J. A. Whiles, G. Wu et al., "Structural evaluation of phospholipid bicelles for solution-state studies of membraneassociated biomolecules," Biophysical Journal, vol. 81, no. 4, pp. 2163-2171, 2001.

[24] J. J. Chou, J. L. Baber, and A. Bax, "Characterization of phospholipid mixed micelles by translational diffusion," Journal of Biomolecular NMR, vol. 29, no. 3, pp. 299-308, 2004.

[25] L. van Dam, G. Karlsson, and K. Edwards, "Direct observation and characterization of DMPC/DHPC aggregates under conditions relevant for biological solution NMR," Biochimica et Biophysica Acta, vol. 1664, no. 2, pp. 241-256, 2004.
[26] A. Andersson and L. Mäler, "Magnetic resonance investigations of lipid motion in isotropic bicelles," Langmuir, vol. 21, no. 17, pp. 7702-7709, 2005.

[27] A. Perálvarez-Marín, A. Barth, and A. Gräslund, "Timeresolved infrared spectroscopy of $\mathrm{pH}$-induced aggregation of the Alzheimer A $\beta 1-28$ peptide," Journal of Molecular Biology, vol. 379, no. 3, pp. 589-596, 2008.

[28] E. O. Stejskal and J. E. Tanner, "Spin diffusion measurements: spin echoes in the presence of a time-dependent field gradient," The Journal of Chemical Physics, vol. 42, no. 1, pp. 288292, 1965.

[29] E. Von Meerwall and M. Kamat, "Effect of residual field gradients on pulsed-gradient NMR diffusion measurements," Journal of Magnetic Resonance, vol. 83, no. 2, pp. 309-323, 1989.

[30] P. T. Callaghan, M. E. Komlosh, and M. Nyden, "High magnetic field gradient PGSE NMR in the presence of a large polarizing field," Journal of Magnetic Resonance, vol. 133, no. 1, pp. 177-182, 1998.

[31] P. Damberg, J. Jarvet, and A. Gräslund, "Accurate measurement of translational diffusion coefficients: a practical method to account for nonlinear gradients," Journal of Magnetic Resonance, vol. 148, no. 2, pp. 343-348, 2001.

[32] L. G. Longsworth, "The mutual diffusion of light and heavy water," Journal of Physical Chemistry, vol. 64, no. 12, pp. 19141917, 1961.

[33] L. Braunschweiler and R. R. Ernst, "Coherence transfer by isotropic mixing: application to proton correlation spectroscopy," Journal of Magnetic Resonance, vol. 53, no. 3, pp. 521-528, 1983.

[34] J. Lind, A. Gräslund, and L. Mäler, "Membrane interactions of dynorphins," Biochemistry, vol. 45, no. 51, pp. 15931-15940, 2006.

[35] D. S. Wishart, B. D. Sykes, and F. M. Richards, "The chemical shift index: a fast and simple method for the assignment of protein secondary structure through NMR spectroscopy," Biochemistry, vol. 31, no. 6, pp. 1647-1651, 1992.

[36] D. S. Wishart, C. G. Bigam, A. Holm, R. S. Hodges, and B. D. Sykes, ${ }^{11} \mathrm{H},{ }^{13} \mathrm{C}$ and ${ }^{15} \mathrm{~N}$ random coil NMR chemical shifts of the common amino acids. I. Investigations of nearestneighbor effects," Journal of Biomolecular NMR, vol. 5, no. 1, pp. $67-81,1995$.

[37] I. Marcotte and M. Auger, "Bicelles as model membranes for solid-and solution-state NMR studies of membrane peptides and proteins," Concepts in Magnetic Resonance A, vol. 24, no. 1, pp. 17-35, 2005.

[38] R. S. Prosser, F. Evanics, J. L. Kitevski, and M. S. Al-AbdulWahid, "Current applications of bicelles in NMR studies of membrane-associated amphiphiles and proteins," Biochemistry, vol. 45, no. 28, pp. 8453-8465, 2006.

[39] J. Danielsson, J. Jarvet, P. Damberg, and A. Gräslund, “Translational diffusion measured by PFG-NMR on full length and fragments of the Alzheimer $A \beta(1-40)$ peptide. Determination of hydrodynamic radii of random coil peptides of varying length," Magnetic Resonance in Chemistry, vol. 40, pp. S89S97, 2002.

[40] J. Shafqat, E. Melles, K. Sigmundsson et al., "Proinsulin Cpeptide elicits disaggregation of insulin resulting in enhanced physiological insulin effects," Cellular and Molecular Life Sciences, vol. 63, no. 15, pp. 1805-1811, 2006.

[41] Y. Ohtomo, A. Aperia, B. Sahlgren, B. L. Johansson, and J. Wahren, "C-peptide stimulates rat renal tubular $\mathrm{Na}^{+}, \mathrm{K}^{+}$ATPase activity in synergism with neuropeptide Y," Diabetologia, vol. 39, no. 2, pp. 199-205, 1996. 
[42] Y. Ido, A. Vindigni, K. Chang et al., "Prevention of vascular and neural dysfunction in diabetic rats by C-peptide," Science, vol. 277, no. 5325, pp. 563-566, 1997.

[43] P. Schlesinger, Y. Ido, and J. Williamsson, "Conductive channel properties of human C-peptide in-corporated into planar lipid bilayers," Diabetes, vol. 47, supplement 1, p. A29, 1998.

[44] P. Tompa, "Unstructural biology coming of age," Current Opinion in Structural Biology, vol. 21, no. 3, pp. 419-425, 2011.

[45] T. Mittag, J. Marsh, A. Grishaev et al., "Structure/function implications in a dynamic complex of the intrinsically disordered Sic1 with the Cdc4 subunit of an SCF ubiquitin ligase," Structure, vol. 18, no. 4, pp. 494-506, 2010.

[46] V. N. Uversky, "Intrinsically disordered proteins from A to Z," International Journal of Biochemistry and Cell Biology, vol. 43, no. 8, pp. 1090-1103, 2011.

[47] O. A. Andreev, A. D. Dupuy, M. Segala et al., "Mechanism and uses of a membrane peptide that targets tumors and other acidic tissues in vivo," Proceedings of the National Academy of Sciences of the United States of America, vol. 104, no. 19, pp. 7893-7898, 2007.

[48] D. Wijesinghe, D. M. Engelman, O. A. Andreev, and Y. K. Reshetnyak, "Tuning a polar molecule for selective cytoplasmic delivery by a $\mathrm{pH}$ (Low) Insertion Peptide," Biochemistry, vol. 50, no. 47, pp. 10215-10222, 2011. 

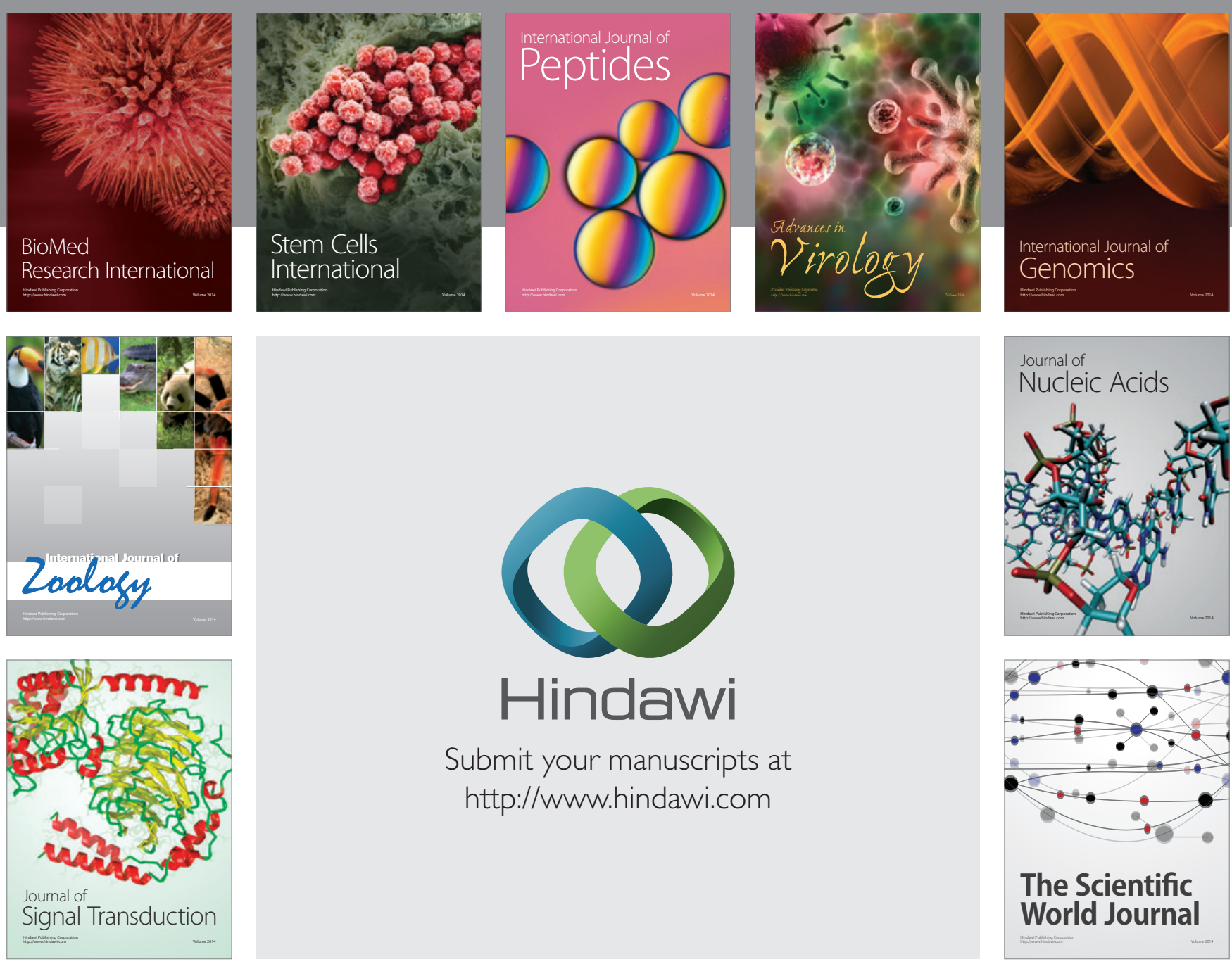

Submit your manuscripts at

http://www.hindawi.com
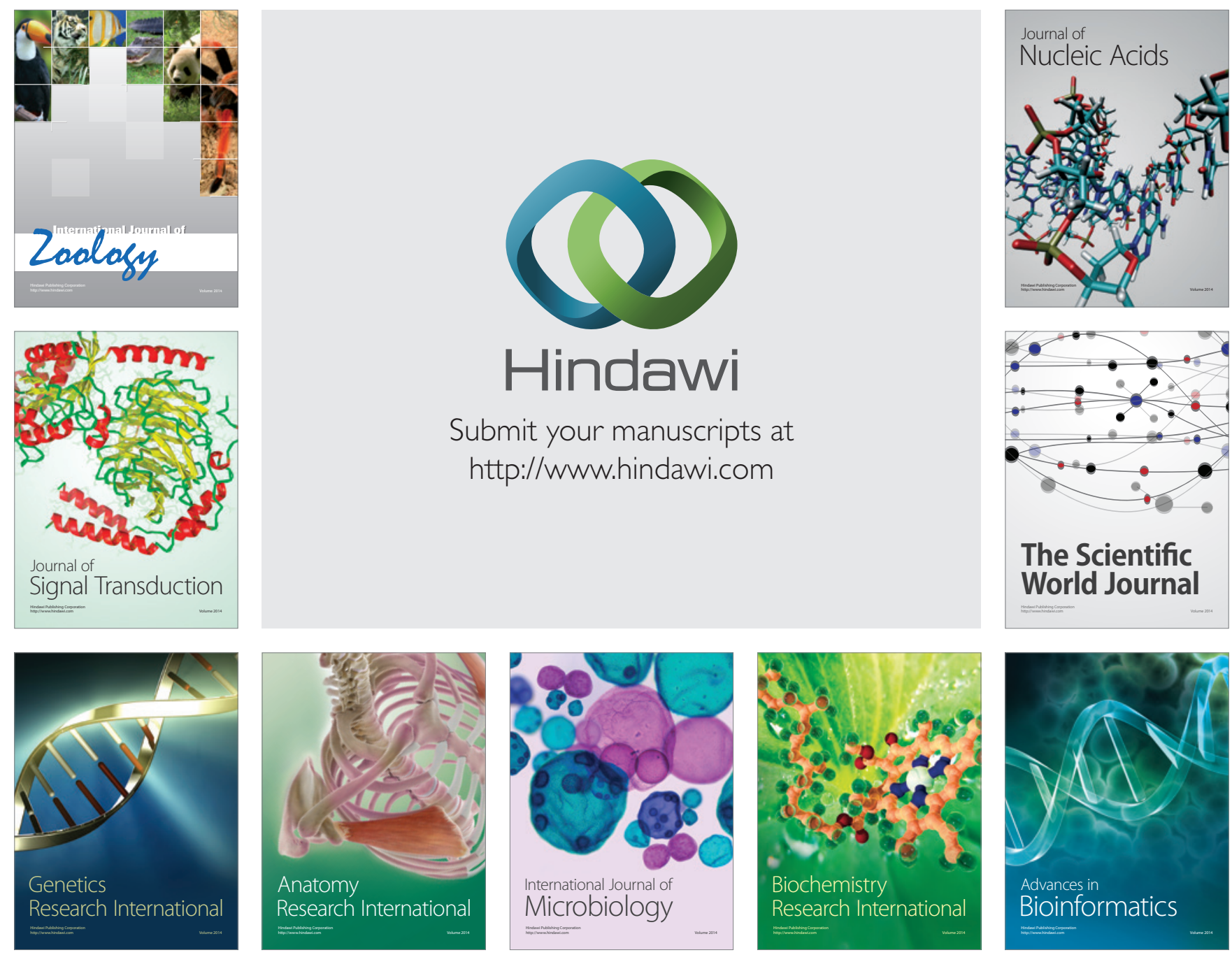

The Scientific World Journal
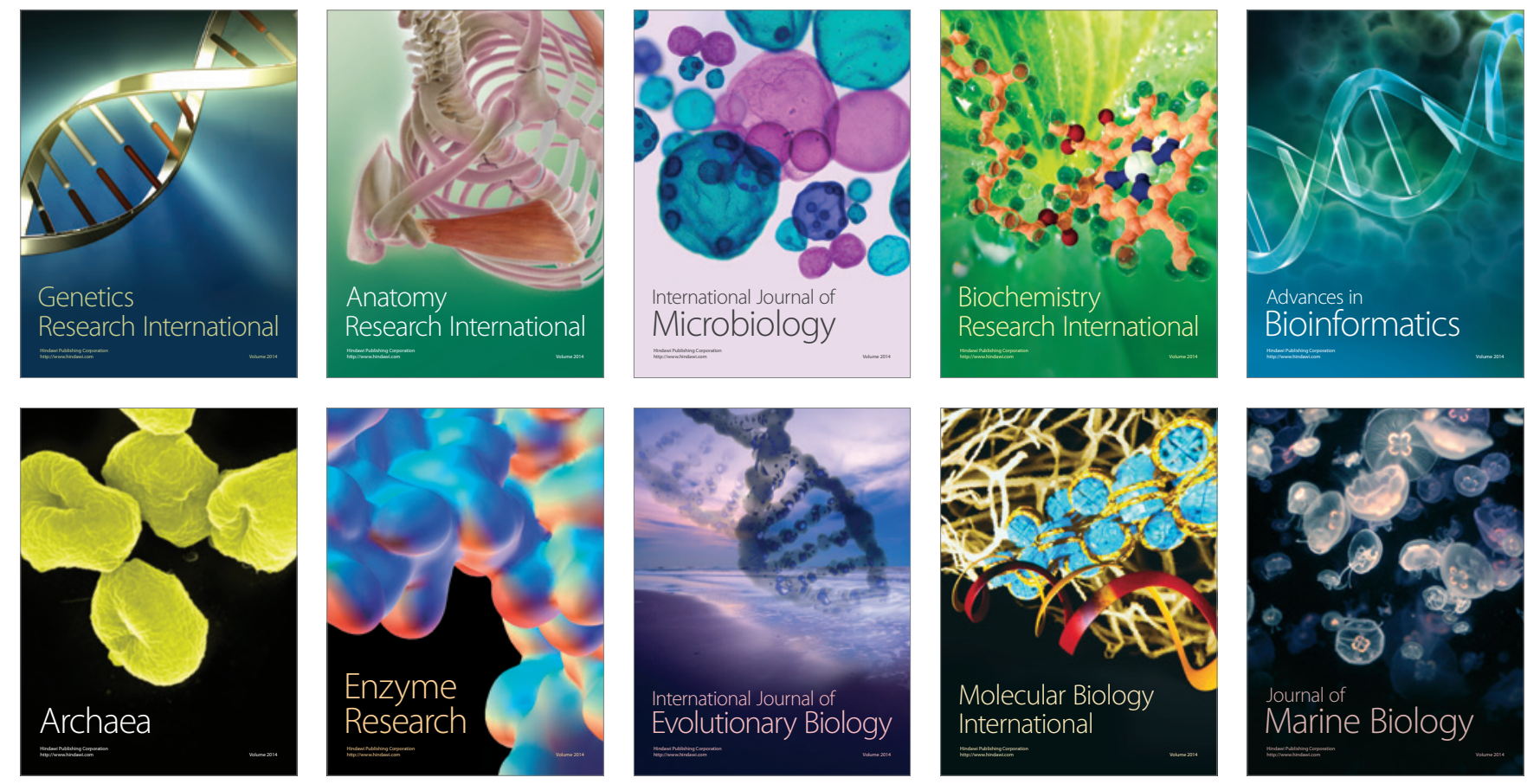